\title{
CONTRIBUIÇÕES DA PSICANÁLISE AO ACOMPANHAMENTO TERAPÊUTICO: ALGUNS APONTAMENTOS PARA A FORMAÇÃO CLÍNICA DO PSICÓLOGO
}

THE CONTRIBUTIONS OF PSYCHOANALYSIS TO THERAPEUTIC ACCOMPANIMENT: NOTES FOR PSYCHOLOGIST'S CLINICAL QUALIFICATION

APORTES DEL PSICOANÁLISIS AL ACOMPAÑAMIENTO TERAPÉUTICO: ALGUNAS NOTAS PARA LA FORMACIÓN CLÍNICA DEL PSICÓLOGO

Ana Lúcia Mandelli de Marsillac
Alana Fantin $^{* *}$
Daphne Fayad
Elina Sartori Pereira
Gabriela Amorin
I*t**icia Vianna
Let*icia Vier Machado
Nicolas Aranda ${ }^{* * * * * * * * *}$
Ricardo Prado Martins

\begin{abstract}
RESUMO
Este artigo reflete sobre as contribuições da psicanálise ao dispositivo clínico do acompanhamento terapêutico (AT). Apresenta o relato de experiência dos integrantes de um projeto de extensão de AT que foi desenvolvido em parceria entre uma universidade pública e a rede municipal de atenção à Saúde Mental, promovendo o acompanhamento de usuários que se encontravam em sofrimento psíquico grave, com o diagnóstico de psicose. Além disso, busca articular essa experiência com a análise teórica da psicanálise, que sustentou essa prática. Dessa forma, o artigo se propõe a dar visibilidade aos desafios e potencialidades encontrados na prática do
\end{abstract}

\footnotetext{
Texto recebido em 15 de abril de 2015 e aprovado para publicação em 2 de fevereiro de 2016.

*Doutora em Artes Visuais: História, Teoria e Crítica pela Universidade Federal do Rio Grande do Sul (UFRGS), mestra em Psicologia Social e Institucional pela UFRGS, professora no Departamento de Psicologia da Universidade Federal de Santa Catarina (UFSC), membro da Associação Psicanalítica de Porto Alegre, psicanalista. E-mail: ana.marsillac@ufsc.br.

**Mestranda no Programa de Pós-Graduação (PPG) em Psicologia da UFSC, psicóloga. E-mail: alanafantin@gmail.com.

***Doutora em Psicologia pela UFSC. E-mail: daphnefayad@gmail.com.

****Graduada no Curso de Psicologia da UFSC. E-mail: elina.sartori@gmail.com.

***** Mestranda no PPG em Psicologia da UFSC. E-mail: gabrielap.amorin@gmail.com.

******Graduanda do Curso de Psicologia da UFSC. E-mail: iclicia@hotmail.com.

*******Doutoranda em Psicologia na USP. Bolsista CNPq e Mestre em Psicologia UFSC. E-mail: leticiaviermachado@gmail.com. *Residente da Residência Integrada em Saúde (RIS) da Escola de Saúde Pública (ESP), psicólogo. E-mail: nicolascparanda@ gmail.com.

*********Residente da residência em Saúde Mental e Psicanálise da Universidade Federal Fluminense (UFF), psicólogo. E-mail: cadopm@gmail.com.
} 
AT bem como a analisar a importância desse dispositivo para a formação clínica do psicólogo, a ampliação do setting terapêutico e o fortalecimento da Reforma Psiquiátrica.

Palavras-chave: Acompanhamento terapêutico. Psicanálise. Clínica. Saúde mental. Psicose.

\section{ABSTRACT}

This article is about the contributions of psychoanalysis to the clinical device for therapeutic accompaniment (TA). It displays the experience report from participants of a TA extension project which was developed in a partnership between a public university and the municipal mental health care network, developing the accompaniment of subjects who were in severe psychological suffering, diagnosed as psychosis. It also seeks to connect this experience with the theoretical analysis of psychoanalysis, which provided support for this practice. Thus, the article aims to give visibility to the challenges and opportunities existing in the AT practice, as well as to examine the importance of this device for psychologists' clinical qualification, the expansion of the therapeutic setting and the strengthening of the Psychiatric Reform.

Keywords: Therapeutic accompaniment. Psychoanalysis. Clinic. Mental health. Psychosis.

\section{RESUMEN}

Este artículo hace una reflexión sobre las contribuciones del psicoanálisis al dispositivo clínico del acompañamiento terapéutico (AT). Presenta el relato de las experiencias de los integrantes de un proyecto de extensión de AT que fue desarrollado en colaboración entre una universidad pública y la red municipal de atención a la salud mental, promoviendo un seguimiento de usuarios que se encontraban en sufrimiento psíquico grave, con el diagnóstico de psicosis. Además de eso, se trata de articular esta experiencia con el análisis teórico del psicoanálisis, que fue el que sustentó esta práctica. De esta forma, el artículo se propone dar visibilidad a los desafíos y potencialidades encontrados en la práctica del AT, así como a analizar la importancia de este dispositivo para la formación clínica del psicólogo, la ampliación del setting terapéutico y el fortalecimiento de la Reforma Psiquiátrica.

Palabras clave: Acompañamiento terapéutico. Psicoanálisis. Clínica. Salud mental. Psicosis. 


\section{INTRODUÇÃO}

$\mathrm{O}$ acompanhamento terapêutico (AT) é um dispositivo estratégico para o trabalho com as psicoses, além de ter se revelado como uma modalidade clínica diferencial na formação dos psicólogos. O trabalho de AT se desdobra no espaço da cidade, ampliando o setting tradicional, e vem sendo utilizado sobretudo nos casos de psicose e, ou, sofrimento psíquico grave, envolvendo a criação de outras propostas clínicas a todos os participantes envolvidos.

O AT configura-se como uma modalidade clínica que vem sendo constituída ao longo dos últimos anos. Iniciou como um trabalho de auxílio psiquiátrico por volta da década de 1960, na Argentina. Com a denominação amigo qualificado, atuava como acompanhamento cotidiano fora das unidades de internação. No Brasil, os profissionais eram chamados de atendentes psiquiátricos e se restringiam a auxiliar os pacientes dentro dos hospitais, buscando a evitação de novas crises. Posteriormente, na década de 1990, a atuação passou a seguir a perspectiva da Luta Antimanicomial, visando ao fortalecimento do cuidado em liberdade. Assim, o AT auxilia na construção de possibilidades de vida fora do manicômio, passando a construir, em conjunto com outros pontos da rede de saúde e assistência, o projeto terapêutico singular de pacientes graves (Reis Neto apud Dutra, Motta \& Santos, 2005).

Neste artigo, analisaremos as contribuições da psicanálise a essa modalidade clínica, com base em nossa experiência no projeto de extensão "Acompanhamento Terapêutico na Rede Pública”. O projeto busca constituir um espaço de atenção e formação em saúde, vinculando a universidade à rede de saúde pública. $\mathrm{O}$ projeto é organizado a partir do dispositivo do AT e de um grupo de supervisão e estudos sobre a clínica da psicose. Desdobra-se em propostas de intervenção vinculadas a esse dispositivo, desenvolvidas por estudantes de graduação e pósgraduação em Psicologia em diálogo com professores e profissionais da rede, e direcionadas a usuários encaminhados pelos Centros de Atenção Psicossocial (CAPS) do Município em questão.

Cabe destacar que o Município sede do projeto conta com uma rede de saúde muito aquém de suas necessidades populacionais. Tal fato inevitavelmente se traduz nas demandas que chegam ao projeto. Os casos que nos foram encaminhados são complexos e desafiam os serviços de saúde pela impossibilidade de serem acompanhados com a atenção que requerem. Diante do contexto de uma rede ainda em construção, $o$ at, ${ }^{1}$ por ter a possibilidade de transitar no espaço intermediário entre a instituição e a rua, permite uma importante aproximação

1Usaremos a denominação "AT" ao dispositivo acompanhamento terapêutico e "at" para o acompanhante terapêutico. 
ao usuário do ponto de vista clínico e institucional, principalmente quando se trata de sujeitos que encontram dificuldades de adesão às formas tradicionais de tratamento.

Com base nos critérios manifestos ou tácitos que cada equipe de saúde mental estabelece para escolher os casos que são encaminhados para acompanhamento terapêutico, Palombini et al. (2004) discriminam diferentes modos de apropriação da modalidade clínica AT pelas equipes, semelhantes àquelas com as quais nos deparamos em nosso projeto. De modo geral, segundo a autora, destacam-se duas direções opostas de apropriação. $\mathrm{Na}$ primeira, a equipe privilegia o encaminhamento dos casos em que não há alteração do quadro clínico, utilizando variados recursos terapêuticos, seja porque o contexto social ou familiar dificulta a adesão a um projeto terapêutico considerado adequado; ou porque o sujeito resiste em aderir ao tratamento. Nessas situaçôes, o at pode se encontrar isolado em sua empreitada, recaindo sobre si a responsabilidade pelo curso de um tratamento que a equipe não acredita mais. $\mathrm{Na}$ segunda direção apontada por Palombini et al. (2004), a equipe encaminha ao AT com base num prognóstico em que o acompanhamento se soma a um conjunto de procedimentos terapêuticos em andamento, ao quais o sujeito vem respondendo de forma positiva. Nessa situação, o acompanhante é um facilitador ou potencializador do processo terapêutico.

João é um usuário que foi acompanhado por nosso projeto após ter sido encaminhado pela rede. Apesar do vínculo positivo com os profissionais de referência do serviço, suas produções delirantes por vezes foram tidas como um desafio às formas de atendimento predominantes no CAPS. Quando o trabalho de AT foi iniciado, João havia saído recentemente de um período em que vivenciou dois surtos psicóticos, deixando de ser "cuidado" por sua companheira e ficando em situação de rua. O CAPS auxiliou na saída da crise, acolhendo, medicando e buscando outra forma de atendimento clínico que evitasse a internação.

No caso de João, o AT somou-se às atividades desenvolvidas no CAPS, num momento em que ele foi acolhido por um casal de primos e mudou de bairro, ainda sofrendo com os efeitos colaterais dos medicamentos. Na discussão de seu PTS (projeto terapêutico singular), a equipe concluiu que seria importante que João tivesse um acompanhamento mais sistemático e próximo de seu território, a fim de possibilitar alguma demarcação num espaço que parecia antes sem limites, à deriva. Ao longo desse acompanhamento, foi possível constatar o potencial terapêutico da clínica na rua, reafirmando a potencialidade da Reforma Psiquiátrica ao trabalhar no território como o lócus psicossocial do usuário e em sua inserção como sujeito no laço social.

2 Os nomes utilizados na descrição da experiência são fictícios. 
Sabemos que a mudança do modelo assistencial em saúde mental no Brasil, instituído por Lei desde 2001 (Lei no 10.216) é um ideal ainda distante. A legislação brasileira, no que se refere à saúde mental coletiva, tem preconizado a desinstitucionalização da loucura, traduzida na ênfase nos serviços substitutivos; no cuidado em liberdade, com a participação da família e comunidade; no tratamento singular a cada um dos usuários. Entretanto as redes de saúde da grande maioria dos municípios brasileiros ainda são muito precárias, criando uma defasagem entre o que é ditado pelas políticas de saúde e aquilo que ocorre de fato, mantendo a tradicional referência ao manicômio como "estratégia" de cuidado. Com pouco investimento, a rede de saúde mental conta com reduzido número de dispositivos e profissionais. Acrescenta-se a isso o tabu que envolve a loucura no laço social. O resultado é que os CAPS, que seriam a referência ambulatorial para os casos de sofrimento psíquico grave, atuam a duras penas para evitar internaçôes como modalidade principal de atenção. Nesse sentido, é possível entender o AT como dispositivo de fortalecimento da Reforma Psiquiátrica, possibilitando que, pelo trabalho contínuo feito de forma singular, paulatinamente os usuários do serviço sejam reinseridos na vida em comunidade. Temos um dispositivo clínico que atua diretamente com o sujeito dito louco e com a relação entre loucura e sociedade.

\section{CLÍNICA E FORMAÇÃO DE PSICÓLOGOS NA CONTEMPORANEIDADE}

Priorizamos, em nosso projeto de AT, valorizar a clínica da psicose no campo da saúde mental coletiva. É importante destacar o significante "clínica" devido a sua estreita relação com o contexto contemporâneo, tanto no que se refere à formação dos psicólogos quanto no que tange ao trabalho no campo da saúde mental. O AT como clínica diz de uma nova compreensão sobre a prática: não se limita ao tratamento tradicional no setting fechado, mas atua como dispositivo junto ao contexto do paciente, sem perder de vista a escuta qualificada.

Iniciemos pelo campo, já que ele se reflete nos currículos acadêmicos. Podemos elencar dois grandes movimentos que corroboram com o enfraquecimento da clínica: aquele que fala do desenvolvimento da ciência moderna e outro, mais recente, que se refere à luta ideológica instituída pela Reforma Psiquiátrica. Michel Foucault, em $O$ nascimento da clínica (1977), analisa o esfacelamento da clínica ao longo da história e observa que, gradualmente, a escuta e o exame clínico foram sendo substituídos pelos exames morfológicos e de imagem. Em outras palavras, se anteriormente a investigação clínica passava necessariamente pelo saber dos pacientes, que informavam sobre seus sintomas, sobre a forma 
de desencadeamento e de alívio, com o avanço nas dissecações dos corpos e na análise material da doença, pela morfologia e imagem dos órgãos, a clínica se condensa, ao ponto de quase prescindir da fala do usuário.

Outro movimento que corrobora com o enfraquecimento da clínica foi reflexo da própria Reforma Psiquiátrica. Pela crítica ao modelo instituído por Pinel, que tinha a clínica como instrumento de sugestão e adestramento dos corpos, a clínica foi paulatinamente colocada como a grande vilã do antigo modelo de saúde mental.

Atualmente, o que vemos é, por um lado, uma grande aposta em estratégias coletivas que priorizam sobretudo a reinserção social dos usuários; por outro, o enfraquecimento de uma clínica do sujeito, que coloque em questão suas demandas específicas. Nesse sentido, sobre o fazer clínico na saúde pública, Campos (2001) tem apontado para certa negação da clínica como uma tendência contemporânea entre os profissionais no campo da saúde mental.

Assim, se avançamos na mudança de paradigmas atrelados a esse campo, em especial com o movimento da Reforma Psiquiátrica, pouco progredimos no que tange à capacidade técnica para atuar diante do sofrimento do usuário nesse novo modelo. A mesma autora explica: tanto a clínica tradicional quanto a clínica ampliada podem ser "degradadas" pela lógica de produção que prioriza números em detrimento de atenção clínica qualificada (Campos, 2001).

Neste sentido, Campos (2001) questiona a separação entre clínica tradicional e clínica ampliada na saúde coletiva, sendo a primeira própria dos saberes especializados, que visam ao tratamento e à reabilitação, e a segunda, ampliada para os diferentes saberes em saúde, que priorizam a promoção e a prevenção em saúde. O risco, conforme a autora, é quando situamos ambas as formas como mutuamente excludentes: a clínica tradicional pode ficar extremamente rígida em suas concepçóes técnicas e em seu reducionismo biomédico, e a clínica ampliada, por sua vez, por mais que expanda seu olhar para a multideterminação e complexidade dos fenômenos saúde/doença, pode negar o saber técnico da clínica, desgastando seu potencial de transformação.

Chegamos, então, à formação do psicólogo nesse contexto. Temos visto nos currículos um modelo de formação generalista, que pretende fugir dos especialismos e da redução dos usuários às questões intrapsíquicas. Investe-se fortemente na transmissão de princípios e fundamentos do Sistema Único de Saúde (SUS) e da Reforma Psiquiátrica, mas se esquece de que o psicólogo, ainda que apropriado desses saberes, necessita de fundamentos epistemológicos e ferramentas clínicas para atuar, observando sempre a complexidade que envolve a constituição dos sujeitos e sua prática clínica. 
Portanto, ainda que a clínica ampliada seja estratégia para qualquer profissional em saúde, a perda das especificidades inerentes a cada formação pode conduzir à fusão esquizofrênica dos saberes e à redução do seu poder de intervenção, tal como analisa Campos (1996). Dito de outro modo, a interdisciplinaridade não é sinônimo da fusão dos saberes, e a clínica ampliada não é sinônimo de confusão nos direcionamentos técnicos. A clínica ampliada é um dispositivo, que se opera na interdisciplinaridade e na intersetorialidade (saúde-assistênciajustiça...), guiada pelo princípio da integralidade da saúde (concepção de sujeito biopsicossocial), que coloca em prática um projeto terapêutico singular a/com cada um, na composição com as redes de serviços e afetivas.

Nesse contexto, o AT configura-se como uma possibilidade de escuta clínica e acompanhamento que singulariza, podendo também ser denominado de clínica ampliada. Quando atrelado às contribuiçôes da psicanálise, sublinhase o foco no trabalho clínico com o sujeito (Elia, 2007), sua história, relações com os outros e com os ideais da cultura, em detrimento da extensa nosografia comumente atrelada aos casos mais graves, ou somente nas condições sociais que parecem selar o destino desses sujeitos. A clínica psicanalítica, atrelada ao dispositivo do AT, busca sublinhar a singularidade de cada caso, articulando diferentes elementos das redes que compõem o projeto terapêutico singular, em um movimento de colocar em análise a implicação de cada ponto da rede com a especificidade que cada sujeito requer. Nesse sentido, o AT se coloca como mais um ponto da rede, que opera sobre o sujeito e seu contexto.

A experiência do AT nesse projeto ajuda a pensar sobre a clínica na formação dos psicólogos. Os princípios da formação generalista nos cursos de Psicologia tendem a ofuscar o fazer específico do psicólogo. Ao colocar em prática e análise: a escuta, a transferência e a imprevisibilidade do setting, sustentamos e qualificamos a formação de profissionais éticos, criativos e responsáveis pela condução do fazer psicológico.

\section{A CLÍNICA DO AT NOS CASOS DE PSICOSE: CONTRIBUIÇŌES DA PSICANÁLISE}

$\mathrm{Na}$ prática do AT, a mediação com a rede se constitui desde o início. Constatamos, na maioria dos casos atendidos, alguns pedidos advindos dos serviços de saúde em relação à atuação dos at. Chegaram muitas demandas para que o at acompanhasse o usuário até o CAPS, ou ainda, que o at intermediasse relações junto à rede de atenção à saúde e assistência social. Assim, foi necessário demarcar o lugar do AT como mais um ponto na rede de cuidado, não assumindo para si a responsabilidade exclusiva de "costurar" a rede. Buscamos manter o 
diálogo com os serviços (profissionais de referência, possíveis reuniōes conjuntas, etc.), tendo sempre como foco o sujeito em acompanhamento, seus movimentos, seu tempo de elaboração e seus desejos.

$\mathrm{Na}$ experiência com João, por exemplo, houve momentos em que a at precisou mediar a relação do usuário com o serviço. Ao acompanhar João e sua cuidadora em uma consulta clínica no CAPS, surgiu uma situação burocrática que se tornou impeditivo para a renovação da receita de medicamentos fundamentais para o usuário. Sua presença e atuação foram importantes no sentido de esclarecer esses aspectos tanto para o serviço quanto para o usuário e a cuidadora, evitando que ele permanecesse sem suas medicações, promovendo também empoderamento e autonomia do sujeito em relação a seu tratamento.

Desde a perspectiva do acompanhante, é possível que o AT gere inicialmente muito temor pelo suposto risco que envolve a saída à rua com os pacientes e por ser, para a maioria dos estudantes, a primeira experiência clínica com pessoas em sofrimento grave. Ainda que se trate de um risco predominantemente imaginário, que envolve o lugar que ocupa a loucura no laço social, a organização dos atendimentos por duplas de acompanhantes tem auxiliado na condução do trabalho, ao exercitar a dimensão da alteridade e a diluição das relações transferenciais em jogo.

As supervisões coletivas, compostas por 4 supervisoras e 10 estudantes, possibilitam a transmissão dessa experiência e a intersecção entre teoria e prática. Qualificamos nossa formação ao colocarmos em análise as demandas que nos chegam, os desdobramentos da transferência e o sujeito acompanhado. Pela transferência, possibilitamos a amarração necessária entre a experiência, a produção e a transmissão (Palombini, 2007).

A dupla tem um efeito importante para o acompanhado também, pois possibilita mais um a testemunhá-lo e a secretariá-lo. Remete aos efeitos das apresentações de pacientes propostas por Lacan, que subverte a lógica didática da psiquiatria clássica, ao dar ênfase à fala do paciente e não exclusivamente ao ensino da teoria. A dupla configura uma triangulação entre os dois at e o paciente. Assim, há um rompimento da relação dual em espelho que poderia ser gerada, permitindo que existam pelo menos dois outros que testemunhem fragmentos da vida desse sujeito, permitindo que se possa compartilhar de forma mais efetiva sua história. Nos casos de psicose, essa dimensão do testemunho corrobora com o compartilhamento e o enlace das produçôes delirantes, possibilitando maior circulação desse sujeito no laço social.

O dispositivo da apresentação de pacientes, exportada da psiquiatria clássica à psicanálise com Lacan, pode produzir importantes efeitos clínicos. Em sua 
versão original, psiquiátrica, exercida por psiquiatras renomados como Esquirol, Charcot e Clérambault, professor de Lacan, essa prática consistia na apresentação e interrogatório do psicótico diante de um grande público, em sua maioria médicos e alunos de psiquiatria. O objetivo da exposição do paciente era extrair dele a verdade sobre a sua doença e forçá-lo a entrar no discurso por meio da adequação à realidade e abandono de seu delírio (Ferreira, 2007).

Lacan, ao contrário, ressignificou a apresentação de pacientes na psicanálise. No lugar da função estritamente clínica, produtora de um saber psiquiátrico essencialmente descritivo e nosológico, a psicanálise deslocou o lugar do saber na apresentação de pacientes: do lado do mestre para o lado do paciente, onde o saber é sempre singular (Ferreira, 2007). É o sujeito quem detém o saber sobre si mesmo e não há tentativa de compreensão de seu delírio que obtenha sucesso. Assim expressava Lacan (1988), no Seminário 3:

O compreensível é um termo sempre fugidio, inapreensível, é surpreendente que ela nunca seja pesada como uma lição primordial, uma formulação indispensável para aceder à clínica. Comecem por não crer que vocês compreendem. Partam da ideia do mal-entendido fundamental. Aí está uma disposição primeira, na falta da qual não há verdadeiramente nenhuma razão para que vocês não compreendam tudo e não importa o quê (p. 30).

É também da falta de compreensão e do mal-entendido que aproximamos o AT da apresentação de pacientes, tal como praticada por Lacan. Evidentemente, há um valor teórico e técnico nessa premissa, mas que se desdobra da postura ética, inaugurada por Freud, de colocar o sujeito em questão, escutá-lo e secretariá-lo na produção de um saber sobre si. João, por exemplo, significa seu sofrimento com base numa explicação fisiológica: seus delírios são resultados da ingestão de carne suína contaminada que lhe renderam larvas no cérebro. Ainda que a doença denominada cisticercose possa provocar confusão mental, entende-se que o que deve ser levado em consideração no acompanhamento são os significantes em jogo e o saber que o sujeito elabora sobre si e sobre seu sofrimento.

Assim como na apresentação, é pela escuta e por meio do compartilhamento da fala que é possível, por exemplo, fortalecer a relação transferencial ou um reposicionamento do sujeito diante de sua fala (Ferreira, 2007). Porém não há garantias: com a psicanálise, trata-se fundamentalmente de uma aposta no sujeito.

Trabalhamos, como bem analisou Carvalho (2004), como esses outros, que constituem fonte de apoio e de nascimento da palavra. 
$\mathrm{Na}$ experiência da psicose, o outro é a principal fonte de desassossego e, contudo, paradoxalmente, poderá se constituir em fonte de alívio e arrimo, desde que capaz da alternância necessária entre sua presença e ausência, para a emergência da palavra no campo simbólico (Carvalho, 2004, p. 143).

Apostar na importância do simbólico na psicose remete-nos não apenas às articulações dos registros propostos por Lacan (2005) (real, simbólico, imaginário), mas há uma diferença essencial estabelecida por Freud, em 1924, em seu texto $A$ perda da realidade na neurose e na psicose. Nesse breve ensaio, Freud descreve os principais mecanismos em jogo na neurose e na psicose, explicando que, em ambas, ocorre uma "perda da realidade", por mecanismos distintos. Nesse processo, Freud indica dois estágios: num primeiro momento, o Eu é retirado da realidade indesejada ou traumática e, num segundo, há uma ação de reparo, compensação dessa perda. Porém, na neurose, trata-se de uma fuga e, na psicose, da criação ou substituição da realidade por outra remodelada.

Freud chama a atenção para o fato de haver, também na neurose, tentativas de substituir a realidade pela fantasia, que opera como uma reserva e serve de refúgio via regressão. Essa distinção é por ele estabelecida nos seguintes termos: na psicose, a realidade fantástica "pretende se pôr no lugar da realidade externa", enquanto que, na neurose, as coisas se passam como numa brincadeira de criança, já que o mundo novo "se apoia de bom grado em uma porção da realidade externa", atribuindo-lhe "um sentido oculto que, de maneira nem sempre correta, chamamos de simbólico" (Freud, 1924/2011, p. 221)³.

A referida realidade externa (compreendida desde a cultura, passando pela linguagem e podendo encarnar os espaços físicos) envolve o conceito de (grande) Outro, de Jacques Lacan, e nos aproxima, mais uma vez, das palavras de Carvalho (2004), quanto a seu lugar paradoxal, ainda que ela considere ali o pequeno outro, o semelhante. Afinal, nas relações com o outro, o Outro se presentifica.

Além disso, Quinet (2006, p. 26) demonstra que o que fundamenta o campo da realidade é o objeto a (objeto causa de desejo), visto que "sua exclusão da linguagem constitui este campo, o qual só se sustenta pela extração do objeto a, que, no entanto, fornece seu enquadre”. Isso acaba por gerar uma problemática ao se falar de transferência na psicose, já que, nessa estrutura, não há extração do objeto a, levando Lacan (apud Quinet, 2006) a formular que o psicótico é aquele que leva seus objetos no bolso, não precisando do Outro para causar seu desejo. Se supomos que o analista, na clínica da neurose, é aquele que faz semblante de objeto a, representando um saber para o analisante, que assim pode associar livremente em direção a seu desejo; com a psicose, certamente a cena muda.

3 A primeira data indica o ano de publicação original da obra, e a segunda, a edição consultada pelo autor; esta só será pontuada na primeira citação da obra no texto. Nas seguintes, será registrada apenas a data de publicação original. 
A questão da transferência na psicose coloca em primeiro plano a promoção do laço social e é uma das raras modalidades de tratamento do mal-estar que considera o louco como sujeito, tanto sujeito de direitos como sujeito do (ao) inconsciente. Nesse sentido, se o que interessa na clínica da neurose é o recalcado e seu retorno, na psicose, trabalha-se com o retorno do foracluído, na forma de delírios e alucinações. Contudo, dizer que o "Nome do pai” está foracluído nas psicoses implica, como nos mostra Quinet (2006, p. 52), certa dificuldade de dialetizar suas relações sociais, não conseguindo circular facilmente pelos diferentes discursos que, considerados como laços sociais, permitem "a metabolização e até mesmo a colonização do gozo que vai até a coletivização" (Quinet, 2006, p. 52).

O louco representaria, com seus neologismos, suas mensagens interrompidas e sua linguagem fragmentada, o avesso dos discursos, denunciando os semblantes e a inconsistência do Outro como garantia da lei. Contudo devemos ressaltar que, mesmo com essa posição em relação aos discursos, é possível que ele se insira em algum campo simbólico, possibilitando, assim, viver de forma mais ou menos compartilhada. Por essa via, o delírio pode ser considerado uma tentativa de entrar no discurso como laço social.

Entendemos, portanto, que o AT, uma vez que acontece e transita justamente na interface do "mundo fantástico" (nas palavras de Freud) e da realidade fática, pode operar de maneira privilegiada para incluir o sujeito, tanto no tratamento, mediante sua fala, sua história e sua singularidade, como nos laços sociais, pelos discursos, as trocas com a vizinhança, a arte, o lazer. O inconsciente "a céu aberto" da psicose se mostra nas ruas, desarranjando hábitos, costumes e provocando a ordem vigente.

O dispositivo do AT vem justamente na contramão do tratamento ao famigerado "louco varrido", que, tirado das ruas da cidade, era mantido isolado do convívio social. Trata-se, por fim, de uma espécie de mediação capaz de proporcionar as vias simbólicas e a emergência de novos sentidos dessa interação entre as realidades e a volta do louco à cena urbana, contagiando a indiferença da cidade com sua diferença.

Ainda que a estrutura psicótica coloque em destaque a dimensão real e imaginária, cabe justamente na clínica resgatar a articulação simbólica que produz significação de sujeito. $\mathrm{O}$ sujeito, por concepção barrado, é posto em questão pela estrutura psicótica. A foraclusão do "Nome do pai", dimensão estrutural da psicose, indica a diferença para com a estrutura neurótica, na qual incide a barra da castração e com ela a organização de uma significação sexual que amarra as demais. Calligaris (1989, p. 13), ao analisar essa temática, sublinha 
a errância psicótica em um mundo onde "todas as significações são significações em si mesmas, não se medem a uma significação que distribui as significações do mundo".

A questão é que, para existir como sujeito, para que seu corpo não seja puramente real, para que não se torne objeto da demanda do Outro, é preciso algum estatuto simbólico. O delírio, dessa forma, revela-se como defesa, que por não ter uma metáfora a qual se referir aparece no real. Trata-se de uma tentativa de amarração, de constituição de uma metáfora e de obtenção de alguma significação de sujeito. Nossa clínica, dessa forma, não busca tamponar o delírio, mas escutá-lo em sua radical singularidade. Para isso, o acompanhante precisa deixar de lado o imaginário que permeia a loucura e, sobretudo, o imaginário que atravessa sua condição de acompanhante terapêutico.

A proximidade ao lócus do acompanhado é outro elemento importante, pois, se, por um lado, nos aproxima das falas que envolvem esse sujeito, por outro, com mais facilidade, corremos o risco de realizar cálculos precisos sobre as relações intersubjetivas que se estabelecem e que constituem o acompanhado. Como se através delas pudéssemos subtrair e definir a posição do sujeito. É importante sublinhar que a condição e posição de sujeito se decide no campo da linguagem. Como bem analisa Lacan (1988), em seu Seminário 3, o sujeito não apenas fala, mas é falado pelo contexto que o cerca, e isso está no cerne da sua condição de sujeito. O que está foracluída é a função paterna, mas ainda assim circulam significantes.

Outro ponto já comentado acima diz respeito à ânsia pela busca de um sentido já conhecido no trabalho interpessoal. Lacan afirma sobre a compreensão que

Há dois perigos em tudo que tange à apreensão de nosso campo clínico. O primeiro é não ser suficientemente curioso. [...] O segundo é compreender. Compreendemos sempre demais, especialmente na análise. Na maioria das vezes nos enganamos (Lacan, 1988, p. 135).

O embate entre falta e excesso de compreensão retoma a análise acerca da transferência e seu manejo com pacientes psicóticos. Cabe destacar que, no trabalho de AT, buscamos compor as contribuições da psicanálise ao campo da saúde mental, considerando os efeitos descritos pela pratique à plusieurs (prática entre vários) (Fernandes, 2005), que remete ao trabalho em rede, realizado por vários profissionais de diferentes instituiçōes, bem como às redes comunitárias, que se configuram como arrimo à loucura.

É importante frisar a riqueza da escuta realizada perto de onde o sujeito vive diariamente nos casos de psicose. Os primeiros acompanhamentos de João, por 
exemplo, foram realizados no contexto institucional do CAPS. Percebia-se a dificuldade de acessá-lo, de estabelecer uma relação mais próxima a ele. Havia ali diferentes vozes que, por vezes, não davam muito espaço para seu tempo. Nesse sentido, a proximidade da dupla de at ao contexto cotidiano do acompanhado incrementou o estabelecimento de uma relação transferencial, permitindo que seu ritmo e questóes singulares pudessem ser desdobradas.

Saber como o sujeito é falado por sua rede psicossocial é imprescindível para distinguir quais significantes destacam-se em sua rede de significações, bem como quais tendem a o aprisionar em diagnósticos e discursos incapacitantes. Assim, apesar de se iniciar o atendimento tendo conhecimento dos relatos do serviço sobre o histórico do paciente, sofrimento predominante e descrição de seus sintomas psicóticos, é fundamental que o trabalho do at se atenha aos desvios que o sujeito pode vir a fazer na fala.

Da mesma forma, é possível haver discursos cristalizados na relação com os familiares ou cuidadores. No caso de João, sua cuidadora relatou à dupla de at que tinha receios sobre João sair e circular pelo bairro por conta da possibilidade de emergência de seus sintomas, caracterizados como "tonturas". Isso havia acontecido uma vez, quando um vizinho a chamou para atender João que estava tonto na rua. Nesse momento, a at acolheu os medos da cuidadora e ajudou a desconstruí-los, a partir da transferência estabelecida. O passo seguinte foi a proposta de ampliar a circulação de João no território, a partir da escuta do desejo.

Após alguns encontros, surgiu a possibilidade de realizar uma caminhada com ele. As ruas do bairro puderam ser exploradas, ao passo que histórias de vida apareceram em seu discurso, associadas aos elementos da cidade que se apresentavam. Nesse movimento de reconstrução de sua própria significação e mapeamento do perímetro do bairro, coube às acompanhantes destacar os significantes que surgiram, possibilitando a demarcação de diferenças e intensidades entre eles. Algo importante para o acompanhamento terapêutico, posto que na estrutura psicótica as significações tendem a ter indistintamente o mesmo valor (Calligaris, 1989).

Lacan sugere, no trabalho com as psicoses, que possamos tomar "ao pé da letra” o que é dito pelo psicótico. Em uma perspectiva de trabalho que sublinha os significantes e se dispóe a recolher os fragmentos dispersos que os psicóticos colocam em jogo, o analista contentar-se-ia, assim, em "secretariálo", abrindo novas possibilidades de manejo da transferência na psicose. Como bem depreendem Costa e Freire (2010), a expressão "secretariar o alienado", no contexto em que foi utilizada por Lacan, significa tomar os elementos e a lógica 
da psicose em sua literalidade, o que quer dizer ser convocado a ocupar um lugar compatível com aquele tomado pela foraclusão, fazendo-se, assim, parceiro nas construçôes que ocorrem.

Essa espécie de parceria que se configura no "secretariar" está duplamente presente no manejo da transferência no AT, uma vez que não se trata apenas de uma postura clínica, mas de literalmente acompanhar o psicótico pelos diferentes espaços da cidade. Além disso, considerada a peculiaridade da transferência na psicose, o dispositivo da dupla permite que se pulverizem os possíveis efeitos persecutórios, injuntivos, decorrentes da posição imaginária ocupada pelo grande Outro (Calligaris, 1989).

Isso implica que a direção do tratamento se dê no sentido de estimular a contextualização dos sintomas na história do sujeito, fazendo-o identificar em seus delírios as palavras ouvidas do Outro. Além disso, o analista pode contribuir para secretariar o psicótico em suas tentativas de estabelecer pares opostos de significantes, além de promover a marcação em sua fala, para que o sentido se precipite (Quinet, 2006, p. 54).

É também neste sentido que fazemos uso das contribuições descritas pelas pratiques à plusieurs (Fernandes, 2005), as quais preconizam que a direção a ser adotada deve ser dada pelo sujeito, e demonstram que os diferentes espaços e diferentes acompanhantes viabilizam uma facilitação desse "afrouxamento" do Outro na relação transferencial.

Ainda que não operemos no setting institucional dos serviços de saúde mental que descrevem as pratiques à plusieurs, acreditamos que o dispositivo da dupla, em rede com os outros profissionais dos serviços, beneficia-se dos efeitos por elas descritos. As implicações da diferença são consideradas no sentido mesmo em que Fernandes, apoiada em Elia (2007), problematiza a escolha dos termos "muitos" ou "vários" como tradução de "plusieurs". Não se trata nem de uma combinação de iguais ("muitos" no sentido de numerosos) nem da conglomeração de diversidades (possível interpretação de "vários"), uma vez que é a singularidade que se tem em conta. A valorização da diferença cabe antes por preconizar-se que a singularidade de cada caso deve guiar o trabalho e a direção do tratamento, bem como que a singularidade das pessoas envolvidas no atendimento (no nosso caso, no acompanhamento) é essencial ao manejo da transferência e ao tratamento em geral que, assim pensado, pode ser enriquecido e ampliado. 


\section{CONSIDERAÇÕES FINAIS}

$\mathrm{O}$ que buscamos com o AT? Nossas primeiras indicações foram no sentido de saber mais sobre esses sujeitos. O que nos contam sobre si, sobre a sua história? $\mathrm{O}$ que os perturba? $\mathrm{O}$ que contam sobre o desencadeamento do delírio, dos sintomas? Essas falas são a preciosidade do nosso trabalho e são elas que direcionam a condução subsequente dos acompanhamentos. No caso de crianças, paralelamente ao trabalho de constituição da relação transferencial com a criança, é fundamental o trabalho com os pais: que lugar essa criança ocupa no seu desejo? Qual sua história? Quais são seus principais sintomas? Como lidam com eles?

Se nossa curiosidade, como bem analisa Lacan, leva-nos a saber mais, tampouco nos serve para que supostamente compreendamos o caso. Questão paradoxal a ser trabalhada na formação, pois nosso intuito é escutar esses sujeitos e, nesse gesto, fazemos hipóteses e, muitas vezes, supomos compreender. Precisamos, entretanto, ter o cuidado para não fecharmos nossas análises em atitudes totalizantes. Kristeva (2002) reforça essa atitude ética ao afirmar que, a cada novo caso, descobrimos uma nova doença da alma.

Nesse sentido, durante o acompanhamento terapêutico de João, percebemos as diferentes possibilidades de atuação clínica do psicólogo, tendo como foco a direção do tratamento pautada em uma relação de compromisso ético com o sujeito. A teoria psicanalítica instrumentalizou a prática e foi tensionada por ela. Assim, não se limitou a um embasamento teórico a ser verificado, mas potencializou a formação em Psicologia, contribuindo na construção da relação com o paciente, oferecendo elementos para uma escuta singular e investimento na relação transferencial, que, ao ser estabelecida, pôde sinalizar caminhos a trilhar junto a João. Foi fundamental secretariá-lo na (re)construção de significações de si e de seu processo de adoecimento, no fortalecimento e no estabelecimento de novos enlaces com o território, vizinhos, familiares e serviços de saúde e assistência. O constante diálogo com sua rede, insistindo na perspectiva da lógica antimanicomial e da clínica ampliada, também trouxe desafios que nos levaram a (re)inventar constantemente a práxis clínica.

As semelhanças entre a prática da clínica tradicional e o AT são várias, mas a grande diferença está na expansão do setting. Lacan (1988), no Seminário 3, é categórico ao afirmar que a relação analítica é algo de artificial, não é uma experiência pura. No AT, isso não é diferente, mas se reveste de elementos que interrogam essas premissas. Sob certos aspectos, ela é tão impura quanto a clínica tradicional, pois ainda temos um, ou no caso, dois acompanhantes e um acompanhado. Pela perspectiva da psicanálise, sustentamos que, mesmo no AT, 
trata-se de uma relação analítica, logo há disparidade e relação transferencial entre esses sujeitos.

Entretanto, no encontro com o acompanhado no espaço aberto, na cidade, em sua casa, transcorrem experiências compartilhadas. Esse é o diferencial do AT, pois, ao acompanhar o sujeito em seu lócus, possibilitam-se pontuações significantes nesse trajeto, onde tudo parece ter o mesmo peso. Secretariar o psicótico, como conduta clínica, ganha todo o seu valor.

A rua é campo fértil para a extração de materiais com os quais o psicótico pode trabalhar na direção de produzir seu sintoma, na sua amarração singular ao laço social. Sem dúvida, a rua, a pólis, é afetada por essa presença da psicose em seu meio, cuja diferença busca excluir. Acompanhar a loucura é, nesse sentido, acompanhar também ao Outro, ao que, da cultura, manifesta-se como negação da diferença, recusando-se à estranheza do laço que a psicose intenta (Palombini, 2007, p. 145).

Esse projeto tem sido um desafio para todos que o compõem, pela complexidade que envolve a clínica das psicoses e os desdobramentos da relação transferencial que o AT coloca em jogo. Acompanhamos e secretariamos o psicótico e, ao mesmo tempo, qualificamos a formação dos novos psicólogos, ampliamos a rede e auxiliamos na reflexão crítica sobre o lugar social da loucura na pólis. Nessa trajetória, a psicanálise tem se revelado ferramenta fundamental. 


\section{REFERÊNCIAS}

Calligaris, C. (1989). Introdução a uma clínica diferencial das psicoses. Porto Alegre: Artes Médicas.

Campos, R. O. (2001). Clínica: a palavra negada - sobre as práticas clínicas nos serviços substitutivos em saúde mental. Saúde em Debate, 25(58), 98-111.

Campos, G. W. S. (1996). A clínica do sujeito: por uma clínica reformulada e ampliada. São Paulo: Pontifícia Universidade Católica de São Paulo, PróSaúde. Recuperado a partir de http://www.pucsp.br/prosaude/downloads/ bibliografia/CLINICAampliada.pdf.

Carvalho, M. C. (2004). Acompanhamento terapêutico: do um ao outro, do porto ao mar. In A. Palombini et al. Acompanhamento terapêutico na rede pública: a clínica em movimento. (pp. 137-140). Porto Alegre: Ed. UFRGS.

Costa, C. A. R. \& Freire, A. B. (2010). Lacan, secretário do alienado. Mental, 8(14), 65-91. Recuperado a partir de http://pepsic.bvsalud.org/scielo. php?script=sci_arttext\&pid=S1679-44272010000100005\&lng=pt\&nrm=iso

Dutra, M. C. B., Motta, J. M. \& Santos, L. G. dos. (2005). Acompanhamento terapêutico e clínica das psicoses. Revista Latinoamericana de Psicopatologia Fundamental, 8(3), 497-514. Recuperado a partir de http://www.scielo.br/ scielo.php?script=sci_arttext\&pid=S1415-47142005000300497

Elia, L. (2007). O conceito de sujeito. Rio de Janeiro: Zahar.

Fernandes, R. L. (2005). Nem “entre vários" nem "entre muitos”. Correio: revista brasileira da Escola Brasileira de Psicanálise, 54.

Ferreira, C. M. R. (2007). Apresentação de pacientes: (re)descobrindo a dimensão clínica. Ágora, 10(2), 295-310.

Foucault, M. (1977). Onascimento da clínica. Rio de Janeiro: Forense Universitária

Freud, S. (1924). A perda da realidade na neurose e na psicose. In P. C. de Souza (Trad.), Obras completas: O eu e o id, "autobiografia" e outros textos (1923-1925). (Vol. 16, pp. 214-221). São Paulo: Companhia das Letras, 2011. (Publicado originalmente em 1924).

Kristeva, J. (2002). As novas doenças da alma. Rio de Janeiro: Rocco.

Lacan, J. (1988). O seminário: Livro 3: as psicoses. Rio de Janeiro: Zahar. 
Lacan, J. (1953/2005). O simbólico, o imaginário e o real. In Nomes-do-Pai. Rio de Janeiro: Jorge Zahar. (Publicado originalmente em 1953).

Palombini, A. L. et al. (2004). Acompanhamento terapêutico na rede pública: a clínica em movimento. Porto Alegre: Ed. UFRGS.

Palombini, A. L. (2007). Vertigens de uma psicanálise a céu aberto: a cidade: contribuições doacompanhamento terapêuticoà clínica na ReformaPsiquiátrica. (Tese de Doutorado). Universidade Estadual do Rio de Janeiro, Programa de Pós-Graduação em Saúde Coletiva, Rio de Janeiro. Recuperado a partir de http://www.lume.ufrgs.br/bitstream/handle/10183/10191/000596452. pdf?sequence $=1$

Quinet, A. (2006). Psicose e laço social: equizofrenia, paranoia e melancolia. Rio de Janeiro: Jorge Zahar. 